\title{
$\kappa$-Opioid System Regulates the Long-Lasting Behavioral Adaptations Induced by Early-Life Exposure to Methylphenidate
}

\author{
Matthew D Wiley', Laura B Poveromo', John Antapasis', Carolina M Herrera' and \\ Carlos A Bolaños Guzmán*,I \\ 'Program in Neuroscience, Department of Psychology, Florida State University, Tallahassee, FL, USA
}

\begin{abstract}
Methylphenidate $(\mathrm{MPH})$ is commonly prescribed in childhood and adolescence for the treatment of attention-deficit/hyperactivity disorders. In rodents, MPH exposure during preadolescence (postnatal days (PD) 20-35) causes decreased sensitivity to drug and natural rewards, while enhancing a negative emotional state characterized by increased sensitivity to aversive situations later in adulthood. It has been proposed that this behavioral profile may be mediated, at least in part, by changes in the expression of dynorphin, the endogenous ligand for $\kappa$-opioid receptors (KORs). Because increases in dynorphin activity and activation of KOR induce aversive states, we examined the possibility that these behavioral deficits may be mediated by changes in KOR function, and that MPH-exposed rats would demonstrate increased sensitivity to the $\kappa$-agonist U-50488. Sprague-Dawley male rats were treated with MPH (2 mg/kg) or its saline vehicle (VEH) during PD20-35. When adults (PD90 + ), these rats were divided into groups receiving saline, U-50488 (5 mg/kg), or norbinaltorphimine $(20 \mathrm{mg} / \mathrm{kg})$, a $\kappa$-antagonist, and their behavioral reactivity to various emotion-eliciting stimuli was assessed. Results show that $\mathrm{MPH}$ exposure decreases cocaine place conditioning and sucrose preference, while increasing vulnerability to anxiety (elevated plus maze)- and stress (forced swimming)-eliciting situations, and that these behavioral deficits can be intensified by U-50488, while being normalized by nor-binaltorphimine treatment. These results are consistent with the notion that dysregulated dynorphin/ $\kappa$-opioid systems may mediate deficits in behavioral responding after developmental MPH exposure. Moreover, these findings further support the idea of $\kappa$-antagonists as potential pharmacotherapy for the treatment of anxiety- and depression-related disorders.

Neuropsychopharmacology (2009) 34, I339-1350; doi:I0.1038/npp.2008. I88; published online I5 October 2008
\end{abstract}

Keywords: methylphenidate; U-50488; nor-BNI; depression; rat

\section{INTRODUCTION}

Attention-deficit/hyperactivity disorder (ADHD) is commonly diagnosed during childhood, affecting around $8 \%$ of school-aged children worldwide (Biederman and Faraone, 2004). Psychostimulant medications are effective for the treatment of ADHD, and methylphenidate (MPH; Ritalin) is one of the most prescribed therapeutic agents (Arnsten, 2006; Zito et al, 2000). Despite its well-documented efficacy in the control of ADHD-related symptoms (Biederman and Faraone, 2005), little is known about the long-term consequences resulting from early-life exposure to MPH (Carlezon and Konradi, 2004; Vitiello, 2001).

Similar to the neurobiological actions of cocaine and amphetamine (Koob et al, 1998), MPH increases dopamine

\footnotetext{
*Correspondence: Dr CA Bolaños Guzmán, Program in Neuroscience, Department of Psychology, Florida State University, I I 07 West Call Street, P.O. Box 306430I, Tallahassee, FL 32306-430I, USA, Tel: + I 850644 2627, Fax: + | 850645 75/8, E-mail: bolanos@psy.fsu.edu Received 17 June 2008; revised 9 September 2008; accepted 16 September 2008
}

in brain reward-related regions, namely the ventral tegmental area (VTA) and the nucleus accumbens (NAc) (Federici et al, 2005), enhances locomotor activity (Askenasy et al, 2007), and regulates sensitivity to abused drugs (Crawford et al, 2007; Wooters et al, 2008). Because prolonged exposure to stimulants results in long-lasting neural adaptations that consequently increase vulnerability to compulsive drug use, stress, and related disorders (Nestler and Carlezon, 2006; Volkow, 2004), research has began to focus on assessing the long-term consequences of developmental exposure to MPH.

Recent studies show that exposing rats to MPH during postnatal days (PD) 20-35, a period approximating preadolescence (ie ages 4-12 years) in humans (Andersen and Navalta, 2004; Spear, 2007), results in decreased sensitivity to cocaine and morphine in adulthood (Andersen et al, 2002; Bolaños et al, 2008). Interestingly, these rats also show increased stress reactivity when confronting adverse situations, and reduced responsivity to various rewards (Bolaños et al, 2003; Mague et al, 2005). The mechanism(s) underlying these effects are unknown. However, it has been 
proposed that these MPH-induced effects may be partly mediated by increases in dynorphin (Carlezon and Konradi, 2004 ), the endogenous ligand for $\kappa$-opioid receptors (KORs) (Chavkin et al, 1982; Corbett et al, 1982).

Similar to other psychostimulants, MPH also increases dynorphin within the NAc in young rats (Yano and Steiner, 2005). There is extensive evidence demonstrating that increased dynorphin and its subsequent KOR stimulation causes aversive and depression-like states (Carlezon et al, 2006; Land et al, 2008; Shippenberg and Herz, 1986), whereas KOR antagonism induces antidepressant-like effects (Mague et al, 2003; Zhang et al, 2007). Given the degree of prescribed use of MPH and the potential for treating individuals not meeting the criteria for this disorder (Rey and Sawyer, 2003), it is essential to characterize the long-term consequences associated with developmental stimulant exposure. Accordingly, these studies were designed to assess whether the MPH-induced behavioral effects are regulated by subsequent KOR stimulation in adulthood. We hypothesized that MPH exposure would result in increased sensitivity to U-50488, a $\kappa$-agonist, whereas treatment with the long-acting $\kappa$ antagonist nor-binaltorphimine (nor-BNI; Horan et al, 1992; Jewett and Woods, 1995) would normalize MPHinduced behavioral deficits.

\section{MATERIALS AND METHODS}

\section{Animals}

Litters containing Sprague-Dawley male rat pups with their dams were obtained from Charles River Laboratories (Raleigh, NC) at PD14. Rats were housed in clear polypropyline boxes containing wood shavings in an animal colony maintained at $23-25^{\circ} \mathrm{C}$ on a $12 \mathrm{~h}$ light/dark cycle in which lights were on between 07:00 and 19:00 hours.

\section{Drugs}

Methylphenidate hydrochloride (MPH), cocaine hydrochloride (COC), ( \pm )-trans-U-50488 methanesulfonate (U50), and nor-BNI, were obtained from Sigma (St. Louis, $\mathrm{MO}$ ). Each drug was dissolved in $0.9 \%$ saline (VEH) and administered in a volume of $1 \mathrm{ml} / \mathrm{kg}$. Doses are based on the salt form of each drug.

\section{Drug Treatments}

MPH $(2 \mathrm{mg} / \mathrm{kg})$ or VEH intraperitoneal (i.p.) injections were given between PD20 and 35 twice daily ( $4 \mathrm{~h}$ apart). From PD20 to 23, MPH- and VEH-treated rats were kept together in the same cage with their dams. At PD24 (weaning), rats were separated by treatment condition into groups of four per cage. At PD45, rats were further separated into groups of two per cage, and were left undisturbed until adulthood (ie 8 weeks after the last injection), when they were divided into subgroups receiving a subcutaneous (s.c.) injection of U50 (0 or $5 \mathrm{mg} / \mathrm{kg}$ ), or nor-BNI (0 or $20 \mathrm{mg} / \mathrm{kg}$ ). Behavioral testing started $15 \mathrm{~min}$ after U50, and $24 \mathrm{~h}$ after the nor-BNI injection. The dose of MPH approximates clinically relevant doses in pediatric patient population (Gualtieri et al, 1982; Kuczenski and
Segal, 2005), whereas the dose of nor-BNI $(20 \mathrm{mg} / \mathrm{kg})$ was chosen based on published reports demonstrating that this dose is selective for KORs (Endoh et al, 1992; Takemori et al, 1988). Because $\kappa$-agonists can induce aversive states (Shippenberg et al, 2007), we used separate groups of control (ie no developmental treatment) rats $(275-325 \mathrm{~g})$ to determine the dose of U50 that would prevent COC-induced place conditioning without inducing place avoidance (see Supplement 1). Except for place conditioning and sucrose preference, behaviors were recorded with a video camera located on the ceiling of separate testing rooms. Behavioral observations and analyses were done by observers with no knowledge of the treatment conditions of each rat. Rats were provided with food and water ad libitum. Experiments were conducted in compliance with the Guidelines for the Care and Use of Laboratory Animals (National Institute of Health, 1996), and approved by Florida State University animal care and use committee.

\section{Place Conditioning}

Experiment 1. Adult rats pretreated with MPH or VEH during preadolescence were used to assess place conditioning to $\mathrm{COC}$ in a three-compartment apparatus (Bolaños et al, 2008). Compartments differed in floor texture, wall coloring, and light intensity. On the preconditioning day (day 0 ), rats were allowed to freely explore the apparatus for 20 min to obtain baseline preference to any of the three compartments (side compartments: $35 \times 27 \times 25 \mathrm{~cm}$; middle compartment: $10 \times 27 \times 25 \mathrm{~cm}, l \times w \times h)$. Only rats showing no spontaneous preference to either compartment were used (unbiased procedure); this accounted for more than $90 \%$ of all of the rats tested. Conditioning trials were given on two consecutive days (day 1 and 2). During these trials, rats received saline (SAL) and were confined to one of the large size compartments of the apparatus for $30 \mathrm{~min}$. After $4 \mathrm{~h}$, rats received $\operatorname{COC}(0,5,10$, or $20 \mathrm{mg} / \mathrm{kg}$, i.p. $)$, and were immediately confined to the opposite side compartment for $30 \mathrm{~min}$. On the final day (day 3; test day), rats received an injection of SAL and were again allowed to freely explore the apparatus for $30 \mathrm{~min}$. Time spent in the drug-paired compartment(s) was assessed during this $30 \mathrm{~min}$ period.

Experiment 2. We determined the dose of U50 that would prevent cocaine-induced place conditioning without inducing place avoidance in naïve (ie no developmental treatment) adult rats. This experiment was performed as described above, with the exception that rats were divided into groups receiving (1) U50 $(0,2.5,5$, or $10 \mathrm{mg} / \mathrm{kg}) 15 \mathrm{~min}$ before receiving SAL, or (2) U50 $(0,2.5,5$, or $10 \mathrm{mg} / \mathrm{kg})$ $15 \mathrm{~min}$ before COC (0 or $10 \mathrm{mg} / \mathrm{kg}$ ), and were confined to one of the side compartments of the apparatus for $30 \mathrm{~min}$.

Experiment 3. Results from experiment 2 demonstrated that $5 \mathrm{mg} / \mathrm{kg}$ U50 attenuated COC-induced place conditioning without inducing place avoidance. Thus, adult VEHand MPH-pretreated adult rats were used to assess the effects of U50 $(5 \mathrm{mg} / \mathrm{kg})$ or nor-BNI $(20 \mathrm{mg} / \mathrm{kg})$ on COCinduced $(10 \mathrm{mg} / \mathrm{kg})$ place conditioning. $\mathrm{VEH}-$ and $\mathrm{MPH}-$ pretreated rats were divided into groups receiving SAL/SAL, SAL/COC, U50/SAL, U50/COC, nor-BNI/SAL, nor-BNI/U50, or nor-BNI/COC. U50 was administered $15 \mathrm{~min}$ prior COC, 
whereas nor-BNI was administered $24 \mathrm{~h}$ before the start of the experiment.

\section{Sucrose Preference}

This test consisted of a two bottle choice paradigm in which rats are given the choice between consuming water $v s$ sucrose (dissolved in water). This paradigm has been used extensively to assess the effects of stress-induced anhedonia (Sampson et al, 1992). Rats were habituated to drink water from two bottles for 5 days. At the start of the experiment (day 6), rats were exposed to ascending concentrations of sucrose $(0,0.25,0.5$, and $1 \%)$ for 2 days per concentration (Bolaños et al, 2003). Water and sucrose consumption were measured at 08:00 and 17:00 hours each day, at which time the position of the sucrose bottle (left or right) was switched. For the experiments involving the KOR drugs, separate groups of VEH- and MPH-pretreated rats were habituated as described. Rats received nor-BNI $(0$ or $20 \mathrm{mg} /$ $\mathrm{kg}) 24 \mathrm{~h}$ before the start of the experiment. The water bottles were removed $2 \mathrm{~h}$ (17:00 hours) before the beginning of the dark phase and rats were left with access to food. Rats then received U50 ( 0 or $5 \mathrm{mg} / \mathrm{kg}$ ) or SAL $15 \mathrm{~min}$ before the start of the dark phase (19:00 hours) at which time were given access to sucrose $(0.5 \%)$ or water for $2 \mathrm{~h}$. Testing duration was chosen based on previous reports assessing the acute effects of U50 on sucrose intake (Badiani et al, 2001; Ruegg et al, 1997). The position of the water and sucrose bottles (left or right) was switched every $30 \mathrm{~min}$ for the duration of the procedure. After the $2 \mathrm{~h}$ test, rats were left undisturbed and their overnight fluid consumption was measured the next morning (08:00 hours). The preference for sucrose over water was used as a measure for rats' sensitivity to reward.

\section{Elevated Plus Maze}

VEH- and VEH-pretreated rats were tested for $5 \mathrm{~min}$ on the elevated plus maze (EPM), a behavioral model of anxietylike behavior. The maze was made of gray plastic and consisted of two perpendicular, intersecting runways $(12 \mathrm{~cm}$ wide $\times 100 \mathrm{~cm}$ long). One runway had tall walls $(40 \mathrm{~cm}$ high) or 'closed arms,' whereas the other one had no walls or 'open arms.' The arms were connected together by a central area, and the maze was elevated $1 \mathrm{~m}$ from the floor. Testing was conducted between 09:00 and 13:00 hours under controlled light conditions ( $\sim 90$ lux $)$. At the beginning of the test, rats were placed in the central area, facing one of the open arms, and total time spent in the open arms was videotaped. We also assessed self-grooming in the 'closed arms' because rats engage in repetitive grooming in response to anxiogenic stimuli (Spruijt et al, 1988). Separate groups of VEH- and MPH-pretreated rats received nor-BNI $(20 \mathrm{mg} / \mathrm{kg}) 24 \mathrm{~h}$, or U50 $(5 \mathrm{mg} / \mathrm{kg}) 15 \mathrm{~min}$ prior the start of the experiment.

\section{Forced Swimming}

The forced swim test (FST) is a 2-day procedure in which rats are forced to swim under inescapable conditions. On day 1, rats are forced to swim for $15 \mathrm{~min}$. Initially, they engage in escape-like behaviors, but eventually adopt a posture of immobility, making only the movements necessary to maintain their head above water. When retested $24 \mathrm{~h}$ later, rats become immobile more quickly (Lucki, 1997); however, antidepressant treatment between forced swim exposures can significantly increase their escape-like behaviors, an effect that has been correlated with antidepressant activity in humans (Cryan et al, 2002). Rats were placed in plastic cylinders $(30 \times 75 \mathrm{~cm})$ filled to $54 \mathrm{~cm}$ depth with $25^{\circ} \mathrm{C}$ water and forced to swim for $15 \mathrm{~min}$. At the end of this period, rats were removed from the water, dried with towels and kept in a warm enclosure for $30 \mathrm{~min}$, and received nor-BNI $(20 \mathrm{mg} / \mathrm{kg})$ or SAL. Cylinders were emptied and cleaned between rats. Twenty-four hours after the forced swim rats were retested $15 \mathrm{~min}$ after receiving SAL or U50 $(5 \mathrm{mg} / \mathrm{kg})$, for $5 \mathrm{~min}$ under identical conditions, and sessions were videotaped. Latency to become immobile, total immobility time, and swimming counts were the dependent variables. Swimming counts were rated at $5 \mathrm{~s}$ intervals during the $5 \mathrm{~min}$ retest. Latency to immobility was defined as the time at which the rat first initiated a stationary posture that did not reflect attempts to escape from the water (Lucki, 1997). To qualify as immobility, this posture had to be clearly visible and maintained for $\geqslant 2.0 \mathrm{~s}$.

\section{Locomotor Activity}

VEH- and MPH-pretreated rats were also tested to examine the effects of U50 $(5 \mathrm{mg} / \mathrm{kg})$ on locomotor activity as indexed by distance traveled $(\mathrm{cm})$ in an open field apparatus $(63 \times 63 \times 26 \mathrm{~cm})$ for $2 \mathrm{~h}$. In addition, distance traveled was assessed in separate VEH- and MPH-pretreated groups $24 \mathrm{~h}$ after the first exposure to forced swimming.

\section{Statistical Analysis}

Statistical significance was measured using mixed-design (between and within variables) analysis of variance (ANOVA) followed by Tukey post hoc test. VEH and MPH exposure was considered the pretreatment, whereas subsequent SAL, COC, and KOR drug exposure (U50 and norBNI) the post-treatment variable(s). When appropriate, Student's $t$-test was used to determine statistical significance of preplanned comparisons. Data are expressed as the mean \pm SEM. Statistical significance was defined as $p<0.05$.

\section{RESULTS}

\section{Effects of MPH Exposure on Cocaine-Induced Place Conditioning in Adulthood}

No conditioning effects were observed in VEH $(n=32)$ or MPH $(n=35)$-pretreated rats conditioned with SAL (Figure 1). Time spent in the COC-paired compartments varied as a function of pretreatment and post-treatment (interaction: $\left.\mathrm{F}_{(3,59)}=9.298 ; p=0.0001\right)$. VEH-pretreated spent significantly more time in COC-paired environments $(10(p<0.05), 20(p<0.05), \mathrm{mg} / \mathrm{kg})$, whereas MPH-pretreated rats did not develop place conditioning to COC $(p>0.05)$. In fact, exposure to $10 \mathrm{mg} / \mathrm{kg} \mathrm{COC}$ induced place avoidance in MPH-pretreated rats. 


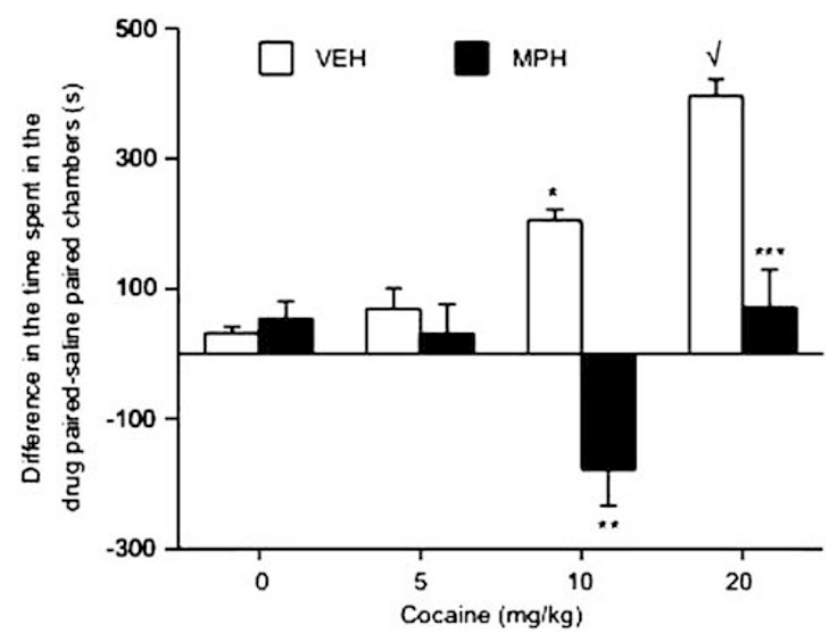

Figure I Developmental exposure to $\mathrm{MPH}$ regulates $\mathrm{COC}$-induced place conditioning $(n=67)$. $\mathrm{MPH}$-pretreated spent significantly less time in COC-paired environments, whereas VEH-pretreated rats spent significantly more time in COC-associated environments in a dose-dependent manner.

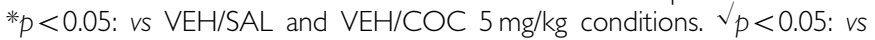
$\mathrm{VEH} / \mathrm{SAL}, \mathrm{VEH} / \mathrm{COC} 5 \mathrm{mg} / \mathrm{kg}$, and the $\mathrm{VEH} / \mathrm{COC} 10 \mathrm{mg} / \mathrm{kg}$ conditions. ** < < 0.05: vs VEH/COC $10 \mathrm{mg} / \mathrm{kg}$; **** $<0.05$ : vs $V E H / C O C$ at $20 \mathrm{mg} / \mathrm{kg}$. Data are presented as the difference in time spent in the COC-paired minus time spent in the SAL-paired compartments during testing day (mean $\pm \mathrm{SEM}$, in seconds).

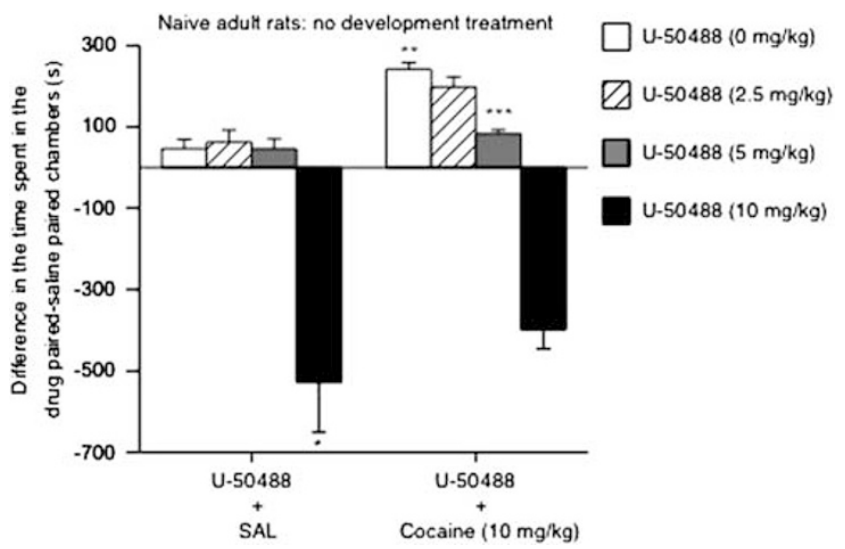

Figure 2 Determination of U50-induced place preference/avoidance in pretreatment naïve rats $(n=64)$. Left panel: $\cup 50$ induced place avoidance at $10 \mathrm{mg} / \mathrm{kg}$ dose (*t $p 0.05$ : vs $0,2.5$, and $5 \mathrm{mg} / \mathrm{kg}$ ). Right panel: $* * * 0.05$ : vs the U50/SAL condition. U50 $(5 \mathrm{mg} / \mathrm{kg})$ blocked COC-induced place conditioning: $* * * * 0<0.05$ vs rats receiving $0,2.5$ and $10 \mathrm{mg} / \mathrm{kg}$ U50 before $10 \mathrm{mg} / \mathrm{kg}$ COC. Data are presented as time spent in the cocaine-time spent in the SAL-paired compartments after conditioning (mean \pm SEM, in seconds).

\section{Effects of U-50488 on Place Conditioning in Treatment Naïve Adult Rats}

Figure 2 shows the effects of U50/SAL (left panel; $n=32$ ), and U50/COC on place conditioning (right panel; $n=32$ ). Time spent in the compartments varied as a function of drug exposure $\left(\mathrm{U} 50 \times \mathrm{COC}\right.$ interaction: $\mathrm{F}_{(3,56)}=2.98$; $p=0.03)$. Rats receiving U50/SAL $(0,2.5$, and $5 \mathrm{mg} / \mathrm{kg})$ did not show place conditioning $(p>0.05)$, whereas those treated with U50 $(10 \mathrm{mg} / \mathrm{kg})$ developed place avoidance $(p<0.05)$. The right panel shows that rats receiving SAL/ COC $(10 \mathrm{mg} / \mathrm{kg})$ developed place conditioning $(p<0.05)$. A low dose of U50 $(2.5 \mathrm{mg} / \mathrm{kg})$ did not block, whereas a moderate dose $(5 \mathrm{mg} / \mathrm{kg})$ attenuated COC-induced place conditioning $(p<0.05)$.

\section{Effects of U-50488 and Nor-BNI on Cocaine-Induced Place Conditioning in MPH-Treated Rats in Adulthood}

Results from experiment 2 revealed that $5 \mathrm{mg} / \mathrm{kg}$ U50 blocked COC-induced place conditioning without inducing place avoidance. Thus, we assessed the effects of U50 $(5 \mathrm{mg} /$ $\mathrm{kg})$, and nor-BNI $(20 \mathrm{mg} / \mathrm{kg})$, on COC $(10 \mathrm{mg} / \mathrm{kg})$-induced place conditioning in VEH- and MPH-pretreated rats $(n=119 ; 8-11$ per condition; Figure 3$)$. A three-way ANOVA indicated that place conditioning varied as a function of developmental pretreatment, KOR, and $\mathrm{COC}$ post-treatment (interactions: $\mathrm{F}_{(2,105)}=3.21 ; p=0.04$ ). For instance, VEH-pretreated spent significantly more time in the COC-paired environments $(p<0.05)$, whereas the MPHpretreated rats consistently avoided them $(p<0.05)$. In addition, VEH-pretreated rats show no preference or avoidance for the U50-paired environments $(p>0.05)$. Furthermore, U50 significantly attenuated COC-induced place conditioning in this group $(p<0.05)$. On the contrary, MPH-pretreated rats avoided COC-paired environments $(p<0.05: v s$ the VEH-pretreated rats in the SAL/COC condition), and showed place avoidance to U50 ( $p<0.05$ : $v s$ the VEH-pretreated rats in the U50/SAL condition). $\mathrm{MPH}$-pretreated rats receiving U50/COC demonstrated a greater magnitude of place avoidance than those receiving SAL/COC $(p<0.05)$, or the VEH-pretreated rats receiving U50/COC $(p<0.05)$. Exposure to $20 \mathrm{mg} / \mathrm{kg}$ nor-BNI reversed the effects of MPH on COC-induced place conditioning, as time spent in the COC-paired compartments did not differ from the VEH-pretreated rats $(p>0.05)$. Moreover, and in line with KOR blockade, U50 did not induce place conditioning or avoidance in the VEH- or $\mathrm{MPH}$-pretreated rats receiving nor-BNI $(p>0.05)$.

\section{Effects of MPH and Subsequent U-50488 and Nor-BNI Exposure on Sucrose Preference in Adulthood}

A mixed design, containing between (ie developmental pretreatment) and within (ie total liquid intake across days) variables repeated measures ANOVA indicated that $\mathrm{MPH}$ pretreatment did not affect the rats' total fluid intake (water + sucrose; Figure $4 \mathrm{~b}$ ) at any of the sucrose concentrations tested. Sucrose preference varied as a function of pretreatment and sucrose concentration (interaction: $\mathrm{F}_{(5,190)}=6.11$; $p=0.001$ ). On the basis of previous observations (Bolaños et al, 2003), we hypothesized that MPH pretreatment would result in decreased sucrose preference when compared to VEH-pretreated rats (preplanned comparison). Unpaired $t$-tests demonstrated that MPH pretreatment $(n=20)$ decreased preference for a $0.25\left(t_{(38)}=2.79 ; p<0.05\right)$, and $0.5 \%\left(t_{(38)}=3.27 ; p<0.05\right)$ sucrose solution when compared to the VEH-pretreated rats $(n=20$; Figure $4 \mathrm{a})$. Differences in sucrose preference between groups were not present at the $1 \%$ concentration.

We assessed the effects of U50 and nor-BNI on sucrose preference in VEH $(n=30)$ - and MPH $(n=36)$-pretreated 


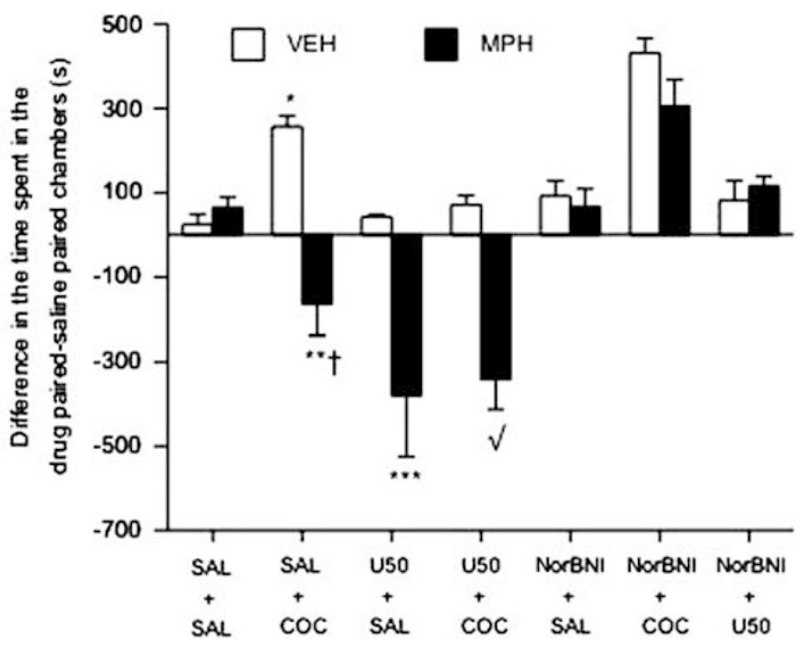

Figure 3 Effects of $\cup 50$ and nor-BNI on COC-induced place conditioning in VEH- and $\mathrm{MPH}$-pretreated rats $(n=1 \mid 9)$. VEH-pretreated developed place conditioning ( $* 00.05$ vs $V E H / S A L$ condition), whereas $\mathrm{MPH}$-pretreated rats avoided COC-paired environments (** $p<0.05$ vs $\mathrm{VEH} / \mathrm{COC}$ condition). $\mathrm{MPH}$-pretreated rats appeared more sensitive to the effects of $U 50(5 \mathrm{mg} / \mathrm{kg})$ : **** $p<0.05$ vs VEH-pretreated rats in the U50/SAL condition. Nor-BNI $(20 \mathrm{mg} / \mathrm{kg})$ reversed the place avoidance induced by $\mathrm{COC}$ and $\mathrm{U} 50$ in $\mathrm{MPH}$-pretreated rats: ${ } p<0.05$ vs $\mathrm{MPH}$ pretreated rats in the SALCOC condition. ${ }^{\dagger} p=0.06$ : vs $\mathrm{MPH}$-pretreated rats in the U50/SAL condition. Data are presented as time spent in the cocaine-time spent in the SAL-paired compartments after conditioning (mean $\pm \mathrm{SEM}$, in seconds).

rats using the sucrose test modifications (ie $2 \mathrm{~h}$ access to the solution) as previously described (Figure 4c). A three-way ANOVA revealed that sucrose preference varied as a function of pretreatment (main effect: $F_{(1,60)}=19.45$; $p=0.0001$ ) and post-treatment (main effect: $\mathrm{F}_{(2,60)}=30.03$; $p=0.0001)$. As expected, MPH-pretreated rats $(n=12)$ showed a decrease in sucrose preference $\left(t_{(20)}=3.3\right.$; $p<0.05)$ as compared to the VEH-pretreated $(n=12)$. U50 $(5 \mathrm{mg} / \mathrm{kg})$ significantly decreased sucrose preference in MPH-pretreated rats $\left(t_{(19)}=2.67 ; p<0.05\right)$, while having a tendency to also decrease sucrose preference in the VEHpretreated group ( $p=0.07$ : $v s \mathrm{VEH} / \mathrm{SAL})$. However, nor-BNI $(20 \mathrm{mg} / \mathrm{kg})$ reversed the effects of MPH on sucrose preference. Because there was a nonstatistically significant tendency for U50 to decrease total fluid intake in VEH- and $\mathrm{MPH}$-pretreated rats (data not shown), we also assessed sucrose preference overnight. Figure $4 \mathrm{~d}$ shows that sucrose preference varied as a function of pretreatment and KOR post-treatment (interaction: $\mathrm{F}_{(2,66)}=7.12 ; p=0.002$ ). The $\mathrm{MPH} / \mathrm{U} 50$ group had a significant decrease in sucrose preference $(p<0.05: v s \mathrm{VEH} / \mathrm{U} 50)$, but this decrease was not different from the MPH/SAL condition $(p>0.05)$. Sucrose preference in the $\mathrm{VEH} /$ nor-BNI group was not different from the VEH/SAL condition $(p>0.05)$; however, nor-BNI reversed the effects of $\mathrm{MPH}$ on sucrose preference.

\section{Effects of U-50488 and Nor-BNI on MPH-Induced Anxiety-Like Behaviors in the EPM}

We assessed the effects of MPH, and subsequent U50 or nor-BNI treatment, on anxiety-like behavior using the EPM (Figure 5a-c). A three-way ANOVA indicated that time spent in the open arms of the EPM was differentially affected by pretreatment (main effect: $F_{(1,50)}=43.21$; $p=0.0001$ ) and post-treatment (main effect: $\mathrm{F}_{(2,50)}=29.98$; $p=0.0001$ ). On the basis of previous observations (Bolaños et al, 2003), we hypothesized that $\mathrm{MPH}$-pretreated rats would spend less time in the open arms of the EPM when compared to VEH-pretreated rats (preplanned comparison). Unpaired $t$-tests demonstrated that MPH-pretreated rats $(n=10$; Figure $5 \mathrm{a})$ spent less time in the open arms than the VEH-pretreated $(n=10)$ rats $\left(t_{(18)}=5.3 ; p<0.05\right)$. Further analysis indicated that U50 decreased $\left(t_{(16)}=2.54\right.$; $p<0.05)$ time spent in the open arms by VEH- $(n=8)$ and MPH-pretreated $(n=10)$ rats; whereas nor-BNI increased $\left(t_{(16)}=3.72 ; p<0.05\right)$ the time spent in the open arms by VEH- $(n=8)$ and MPH-pretreated $(n=10)$ rats. Although nor-BNI increased time in the open arms in both groups, $\mathrm{MPH}$-pretreated rats spent less time than the VEHpretreated rats $(p<0.05)$ in the open arms. However, time spent in the open arms by rats in the MPH/nor-BNI condition was higher than that observed in the MPH/SAL group ( $p<0.05$; Figure 5a). A separate three-way ANOVA revealed that entries into the open arms also varied as a function of pretreatment (main effect: $F_{(2,50)}=13.26$; $p=0.0006$ ) and post-treatment (main effect: $\mathrm{F}_{(2,50)}=14.61$; $p=0.0001)$. The VEH-pretreated had higher entries into the open arms than the $\mathrm{MPH}$-pretreated rats $\left(t_{(18)}=2.55\right.$; $p<0.05$; Figure 5b). U50 did not affect the VEH-pretreated, but did induce a trend towards a decrease in open arm entries in the MPH-pretreated rats as compared to the MPH/SAL condition $(p=0.07)$. Nor-BNI significantly increased entries into open arms by both VEH- and MPHpretreated rats $(p<0.05)$. Self-grooming behavior varied as a function of pretreatment and post-treatment (interaction: $\left.\mathrm{F}_{(2,50)}=7.15 ; p=0.002\right)$. The $\mathrm{MPH}$-pretreated rats had higher self-grooming counts than VEH-pretreated rats $(p<0.05 ;$ Figure $5 c)$. There was a tendency towards an increase in self-grooming in VEH-pretreated $(p=0.07)$, whereas self-grooming in the $\mathrm{MPH}$-pretreated rats was significantly decreased by U50 ( $p<0.05$ : vs MPH/SAL). NorBNI decreased self-grooming in the VEH- and MPHpretreated rats.

\section{Effects of U-50488 and Nor-BNI on MPH-Induced Effects on Forced Swimming Behavior}

We used the FST to study rats' responses to stressful conditions (Figure 6a-f). MPH-pretreated $(n=10)$ had shorter latency to immobility on day 2 of the FST $\left(\mathrm{F}_{(1,16)}=5.6 ; p=0.03\right)$ than the VEH-pretreated $(n=8)$ rats (Figure 6a). MPH-pretreated had higher levels of total immobility $\left(\mathrm{F}_{(1,16)}=6.7 ; p=0.01\right)$, and lower swimming counts $\left(\mathrm{F}_{(1,16)}=5.8 ; p=0.02\right)$, than the VEH-pretreated rats (Figure $6 \mathrm{~b}$ and $\mathrm{c}$ ). The effects of the $\kappa$-drugs on latency to immobility varied as a function of pretreatment and posttreatment (interaction: $\mathrm{F}_{(1,40)}=4.1 ; p=0.049$; Figure 6a). U50 did not affect VEH-pretreated rats' latency to immobility, total immobility, or swimming counts $(n=20$; Figure $6 \mathrm{a}-\mathrm{c})$, although there was a tendency for U50 to decrease swimming counts. However, rats in the MPH/U50 condition $(n=24)$ showed shorter latencies to immobility $(p<0.05)$, higher levels of total immobility $(p<0.05)$, and decreased swimming counts $(p<0.05)$ than the VEH/U50 

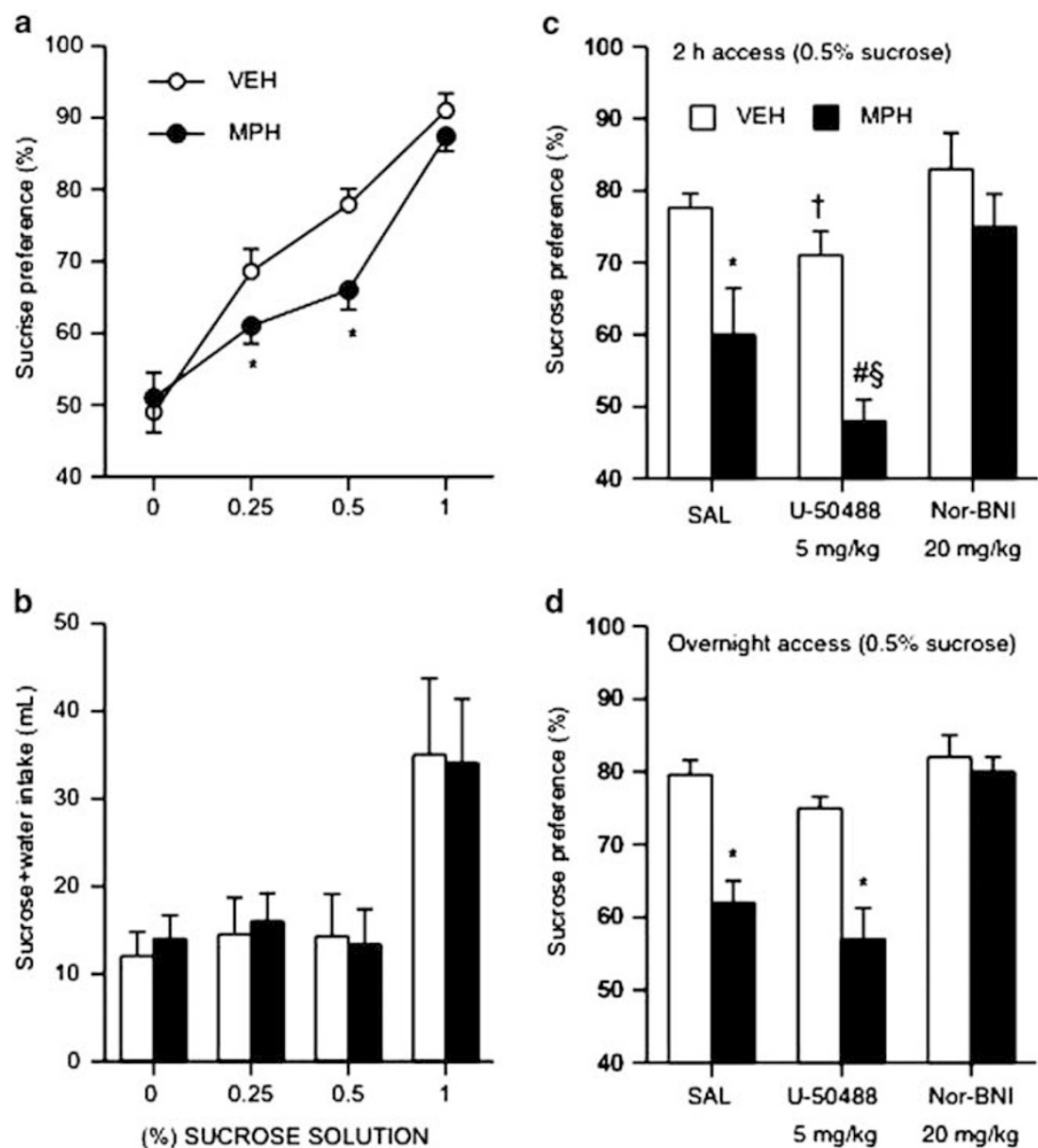

Figure 4 Developmental exposure to $\mathrm{MPH}$ and subsequent U50 and nor-BNI treatment on sucrose preference (a-d). (a) MPH-pretreated showed decreased sensitivity to the rewarding effects of sucrose when compared to the VEH-pretreated rats. *Different at $0.25 \%(p<0.05)$ and $0.50 \%$ sucrose $(p<0.05)$. (b) VEH or MPH pretreatment did not affect total fluid (sucrose + water) intake. (c) $U 50(5 \mathrm{mg} / \mathrm{kg})$ reduced sucrose $(0.5 \%)$ preference in both $\mathrm{VEH}$ - and MPH-pretreated rats given $2 \mathrm{~h}$ access to the solution. ${ }^{*} p<0.05$ : vs MPH/SAL; ${ }^{\dagger} p<0.07$ : vs VEH/SAL; ${ }^{\#} p<0.05$ : vs VEH/U50; ${ }^{\S} p<0.05$ : vs MPH/ SAL. (d) U50 did not change overnight sucrose preference (0.5\%). Nor-BNI restored sucrose preference in VEH- and MPH-pretreated rats. Data are presented as percent preference between $\mathrm{MPH}$ and VEH conditions $(n=106)$.

group. U50 treatment resulted in even shorter latency to immobility when compared to the MPH/SAL condition $(p<0.05)$. However, U50 did not affect total immobility or swimming counts when comparing the MPH-pretreated groups $(p>0.05)$. Rats in the MPH/nor-BNI condition did not show differences in latency to immobility, total immobility or swimming counts when compared to the VEH/nor-BNI condition (Figure 6a-c). As can be seen in Figure $6 \mathrm{~d}-\mathrm{f}$, the antidepressant effects of nor-BNI were still apparent 4 -weeks after exposure to the $\kappa$-antagonist. Together, these findings indicate that $\kappa$-antagonist treatment can normalize the MPH-induced behavioral deficits.

\section{Effects of U-50488 on Locomotor Activity in VEH- and} MPH-Treated Rats in Adulthood

MPH-pretreated had less spontaneous ambulatory counts in response to a novel environment (ie the open field) during the first $10 \mathrm{~min}$ of the session than the VEH-pretreated rats $\left(t_{20}=-5.3 ; p=0.04 ; n=22\right)$. However, an acute injection of U50 $(5 \mathrm{mg} / \mathrm{kg})$ did not affect locomotor activity in either of the groups (Figure 7a).
Because MPH-pretreated rats showed lower levels of locomotion for the first $10 \mathrm{~min}$ in the open field (Figure 7a), it is conceivable that the effects observed in the FST might be due to locomotor impairment in these rats. Thus, we had additional control groups in which VEH $(n=6)$ - and MPH $(n=6)$-pretreated rats were exposed to the FST only on day 1 . The following day, rats were placed in the open field for $1 \mathrm{~h}$, instead. No changes in locomotor activity were evident in VEH- or MPH-pretreated rats (Figure 7b).

\section{DISCUSSION}

The present findings further show that early-life MPH exposure results in decreased responsiveness to rewarding stimuli while enhancing an emotional state characterized by increased sensitivity to aversive situations. These results also demonstrate that these MPH-induced deficits can be intensified, under certain conditions, by subsequent exposure to U50488, or normalized by nor-BNI. MPHpretreated rats did not consistently approach environments associated with doses of cocaine that readily induced place preference in the VEH-pretreated rats, and 
a

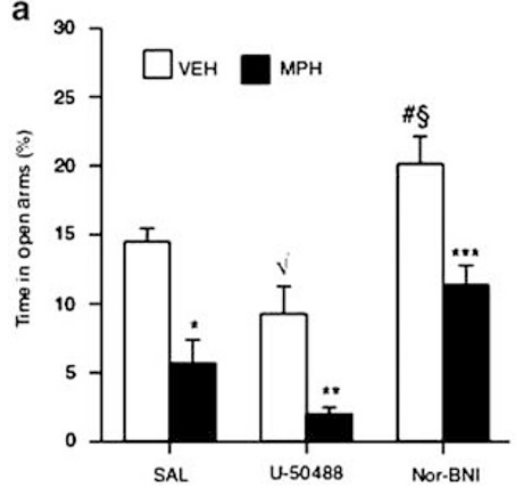

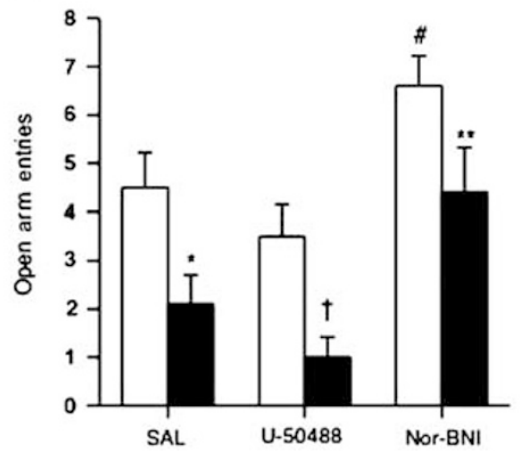



Figure 5 Developmental exposure to $\mathrm{MPH}$ and subsequent $\mathrm{U} 50$ and nor-BNI treatment regulate responses to anxiogenic stimuli $(n=56)$. (a) Rats in the $\mathrm{MPH} / \mathrm{SAL}$ condition spent significantly less time in the open arms of the EPM than rats in the VEH/SAL group $(* p<0.05)$. U50 significantly decreased time in open arms in VEH- ( $p<0.05$ : vs VEH/SAL) and $\mathrm{MPH}$-pretreated rats (** $p<0.05$ : vs VEH/U50). Nor-BNI significantly increased time in open arms in VEH$\left({ }^{\#} p<0.05\right.$ : vs VEH/SAL; ${ }^{\$} p<0.05$ : vs VEH/U50) and MPH-pretreated (**** $p<0.05$ : vs MPH/SAL) rats. (b) Rats in the MPH/SAL condition had significantly less entries into the open arms of the EPM than rats in the VEH/SAL group $(* p<0.05)$. U50 had no effect in the VEH-pretreated rats, while inducing a trend towards a decrease in open arm entries in the MPH-pretreated rats. Nor-BNI increased open arm entries in VEH- ( ${ }^{\#} p<0.05$ : vs MPH/Nor-BNI) and MPHpretreated (** $<0.05$ : vs MPH/U50) rats. (c) Rats in the MPH/SAL condition spent significantly more time engaged in self-grooming in the closed arms of the EPM than rats in the VEH/SAL condition (* $p<0.05)$. U50 treatment decreased grooming in MPH- $(* * *<0.05$ : vs $M P H / S A L)$, while slightly increasing grooming in VEH-pretreated rats ( ${ }^{\dagger} p=0.07$ : vs $\left.\mathrm{VEH} / \mathrm{SAL}\right)$. Nor-BNI decreased grooming in $\mathrm{VEH}-(* * * * * 0.05$ : vs $\mathrm{VEH} / \mathrm{U} 50)$ and $\mathrm{MPH}$-pretreated rats $($ **** $<0.05$ : vs $\mathrm{MPH} / \mathrm{SAL}$ ). Data are presented as percent time spent (mean $\pm \mathrm{SEM}$ ) in the open arms, and as self-grooming counts (mean $\pm \mathrm{SEM})$ in the closed arms.

showed attenuated preference for sucrose (Andersen et al, 2002; Bolaños et al, 2003; Carlezon et al, 2003). Cocaine has both rewarding and aversive properties, and it is possible that the place avoidance observed in the MPHpretreated rats is caused by a decrement in cocaine's rewarding effects (ie tolerance to the rewarding effects of the drug), which, in turn, unmasks other aversive effects of cocaine (Ettenberg, 2004). Alternatively, it is conceivable that MPH-pretreated rats are more sensitive to cocaine, and that intermediate doses (ie greater than $5 \mathrm{mg} / \mathrm{kg}$ and lower than $10 \mathrm{mg} / \mathrm{kg}$ ) could have induced place conditioning. Nevertheless, these findings are analogous with demonstrations that molecular manipulations that reduce the rewarding effects of cocaine often lead to cocaineinduced place aversions (Carlezon et al, 1998; Iñiguez et al, 2008; Olson et al, 2005). The decrease in sucrose preference is likely due to MPH's ability to alter responsiveness to the rewarding effects of the solution, because the total liquid intake during testing did not differ between treatment groups (Figure 4b). These results are consistent with demonstrations that developmental exposure to MPH leads to long-lasting neuroadaptations that result in diminished sensitivity to the rewarding effects of cocaine and morphine, and decreased motivation for natural rewards (Andersen et al, 2002; Bolaños et al, 2003, 2008; Mague et al, 2005).

MPH-pretreated rats appeared more sensitive to KOR activation as they reliably avoided environments paired with a dose of U-50488 $(5 \mathrm{mg} / \mathrm{kg})$ that did not induce place avoidance in VEH-pretreated rats. In addition, exposure to U-50488 attenuated cocaine place conditioning in VEHpretreated rats (Crawford et al, 1995), while intensifying the $\mathrm{MPH}$-induced avoidance for cocaine-paired environments, and their deficits in sucrose preference. It must be noted, however, that U-50488 also had a tendency to negatively influence sucrose preference in VEH-pretreated rats. The mechanism(s) underlying these effects are unknown.
Rewarding stimuli increase dopamine in the VTA-NAc reward pathway, whereas attenuated dopamine transmission is associated with negative emotional states characterized by increased sensitivity to adverse situations (Nestler and Carlezon, 2006). Stimulation of KORs decreases the firing activity of dopamine neurons and inhibits dopamine release within the NAc (Di Chiara and Imperato, 1988; Manzanares et al, 1991). $\kappa$-Agonists do not induce reward, are not self-administered (Kuzmin et al, 1997) and, at high doses, induce aversive states (Land et al, 2008; Mucha and Herz, 1985). Thus, under normal conditions, U-50488 would attenuate cocaine and sucrose reward by stimulating KORs located in dopamine terminals within the NAc, thereby inhibiting dopamine release from these terminals (Di Chiara and Imperato, 1988; Spanagel et al, 1992). Accordingly, the enhanced behavioral reactivity observed in the MPHpretreated rats could be indicative of heightened sensitivity of dynorphin/KOR systems because these rats showed robust place avoidance in response to a dose of U-50488 that had no significant behavioral effects in VEH-pretreated rats.

Decreased sensitivity to rewarding stimuli can be interpreted as a sign of anhedonia (inability to experience pleasure, a core symptom in human depression) in animal models (Nestler and Carlezon, 2006). These findings show that the MPH-induced deficits in cocaine and sucrose reward can be restored to normal levels by nor-BNI. Similar to the effects of some antidepressant drugs, nor-BNI increases dopamine transmission in the NAc and striatum (Maisonneuve et al, 1994; Shippenberg et al, 2007; You et al, 1999); therefore, given that depression and its deficits in appetitive motivation (anhedonia) are linked to impaired functioning of dopamine systems (Nestler and Carlezon, 2006), it is possible that nor-BNI enhances dopamine transmission in reward-related brain areas to reverse depression-like behaviors after developmental MPH exposure. 
a

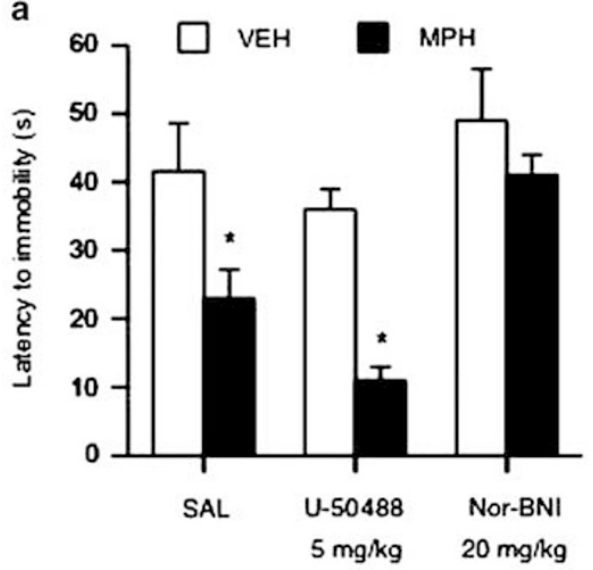

b



c

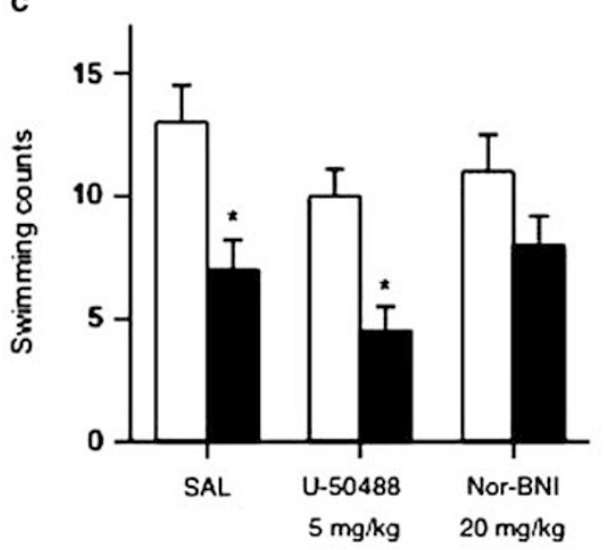

d

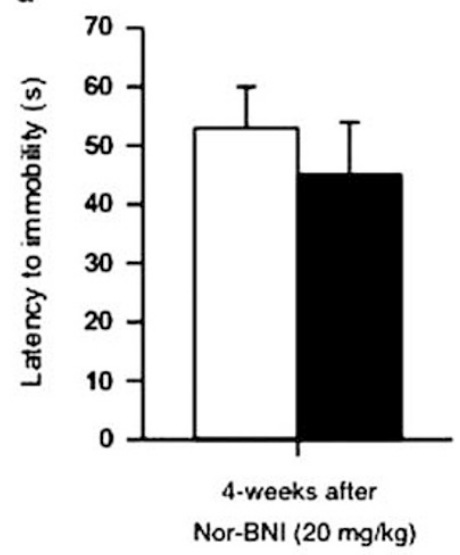

e



f

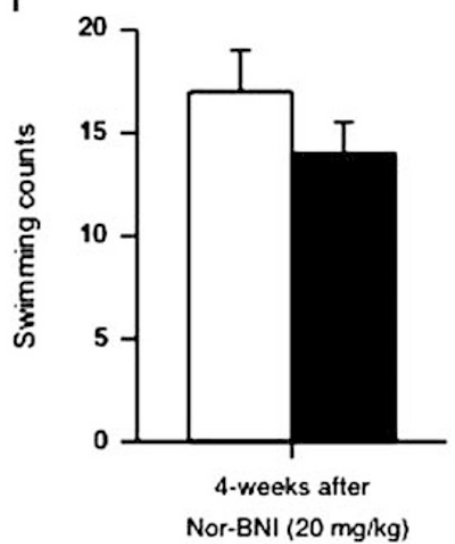

Figure 6 Developmental exposure to $\mathrm{MPH}$ and subsequent $\mathrm{U} 50$ and nor-BNI treatment regulate responsivity to forced swim stress ( $n=62$ ). (a) Rats in the MPH/SAL condition had shorter latencies to immobility than rats in the VEH/SAL group on day 2 of the FST (*P $<0.05)$. U50 further decreased, whereas nor-BNI treatment normalized latency to immobility in MPH-pretreated rats. (b) Rats in the MPH/SAL and MPH/U50 conditions showed increased total immobility, whereas nor-BNI treatment decreased total immobility. (c) Rats in the MPH/SAL and MPH/U50 conditions showed decreases in swimming behavior. Nor-BNI treatment did not affect swimming in either the $\mathrm{VEH}$ - or $\mathrm{MPH}$-pretreated rats. (d-f) $\mathrm{VEH} / \mathrm{nor}-\mathrm{BNI}$ and $\mathrm{MPH} / \mathrm{nor}-\mathrm{BNI}$ treatments showed no differences in latency to immobility, total immobility, or swimming counts 4 weeks after treatment on day 2 of the FST. Data are presented as latencies to become immobile, total immobility (in seconds) or swimming counts (mean \pm SEM).

MPH also rendered rats more vulnerable to adverse situations (Bolaños et al, 2003; Britton et al, 2007; Carlezon et al, 2003). MPH-pretreated rats spent significantly less time in the 'open arms' of the EPM, and significantly more time engaged in self-grooming, a well-known behavioral response to anxiety-eliciting situations. Further studies with the FST found that MPH exposure decreases latency to immobility, an effect opposite to those observed after antidepressant treatments (Cryan et al, 2002). Though similar to the findings with reward-related behaviors in that U-50488 intensified, whereas nor-BNI reversed the anxiogenic and depression-like behaviors induced by MPH, U50488 also decreased the time spent in the open arms, and had a tendency to increase self-grooming in VEH-pretreated 

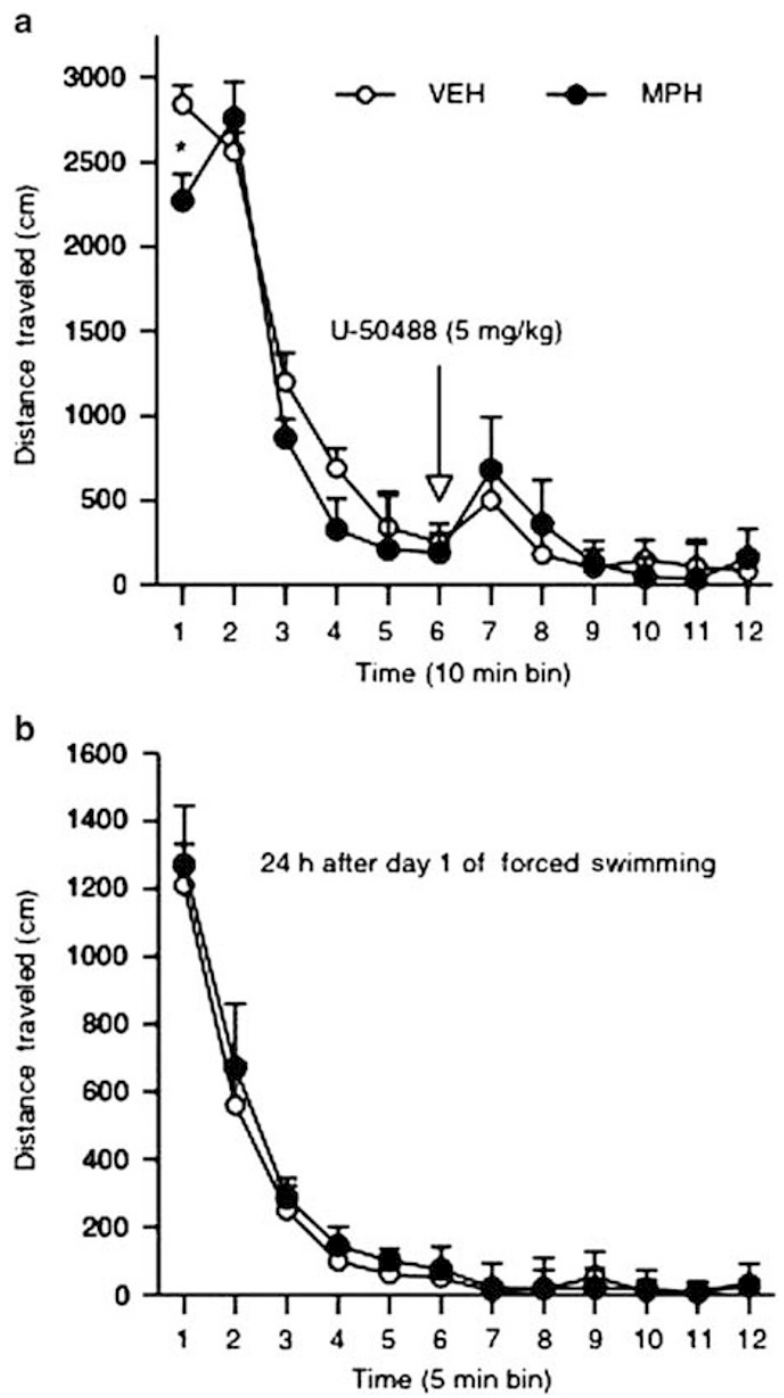

Figure 7 Developmental exposure to $\mathrm{MPH}$ and subsequent $\mathrm{U} 50$ effects on locomotor activity. (a) MPH-pretreated rats showed lower motor activity when compared to the $\mathrm{VEH}$ condition during the first 10 min of the test $(* p<0.05)$. Acute $\cup 50$ treatment did not influence locomotion in either of the groups $(n=22)$. (b) $\mathrm{VEH}$ - and $\mathrm{MPH}$-pretreated rats had no differences in locomotor activity $24 \mathrm{~h}$ after exposure to day I of FST $(n=12)$. Data are presented as mean total distance traveled (mean \pm SEM, in $\mathrm{cm}$ ).

rats. The decreased latency to immobility observed in the MPH-pretreated rats did not result from impaired motor activity because these rats did not show deficits in locomotion $24 \mathrm{~h}$ after day 1 of forced swimming, or after U-50488 exposure (Figure 7a and b). U-50488 induces hyperlocomotion at low, and hypolocomotion at higher (ie greater than $5 \mathrm{mg} / \mathrm{kg}$ ) doses in mice (Kuzmin et al, 2000). We observed increased locomotion after U-50488 treatment, however, the magnitude of the increase was not different between the groups (Figure 7a). The basis for U-50488's effects on motor activity is unknown. It is speculated that different KOR populations, located in different brain regions, may mediate U-50488 effects (Charntikov et al, 2008; Kuzmin et al, 2000). This notion is intriguing because U-50488 induces hyperactivity in developing rats, while inducing hypoactivity in adult rats (Collins et al, 1998;
McDougall et al, 1997), yet it attenuates drug reward in developing and adult rats in a similar manner (Bolaños et al, 1996; Crawford et al, 1995).

The effects produced by nor-BNI are similar to those observed after treatment with antidepressants. Antidepressant medications exert their mood-elevating effects after prolonged (ie weeks) administration (Nestler et al, 2002), and preclinical studies show that depression-like behaviors can be reversed after prolonged treatment (Berton et al, 2006; Bolaños et al, 2008; Krishnan et al, 2008). Interestingly, the nor-BNI-induced antidepressant-like effect was still apparent 4 weeks after a single exposure to the drug (as measured in the FST; Figure 6d). The basis for nor-BNIinduced effects in the FST is unclear. Nor-BNI is known for its long-lasting antagonistic actions at KORs (Horan et al, 1992; Jewett and Woods, 1995), however, this $\kappa$-antagonist may not have long-term efficacy in the FST (Zhang et al, 2007). It is reasonable to assume that the discrepancies between Zhang et al, and our results are due to differences in experimental conditions. Nevertheless, these findings parallel those demonstrating that stimulation of KOR induces depression-like effects, whereas KOR antagonism produces anxiolytic and antidepressant-like effects (Knoll et al, 2007; Mague et al, 2003; McLaughlin et al, 2003; Pliakas et al, 2001).

The behavioral profile induced by early-life MPH exposure is indicative of long-lasting changes in reward pathways resulting in altered behavioral reactivity to drugs of abuse while concurrently inducing depression-like states (Nestler and Carlezon, 2006). It has been proposed that the mechanism(s) underlying these effects may be partly mediated by changes in CREB/dynorphin activity (Carlezon and Konradi, 2004). Our findings demonstrating enhanced behavioral responsivity to KOR stimulation, and reversal of MPH-induced effects by KOR antagonism, lend support to this notion. It must be noted, however, that we did not run U-50488 or nor-BNI dose-response experiments in MPHpretreated rats, and it is possible that the doses used in this study were too high. It is also possible that different drug doses may have had varied effects because we noticed that although $5 \mathrm{mg} / \mathrm{kg} \mathrm{U}-50488$ did not influence locomotion in the VEH- or MPH-pretreated rats, it tended to negatively influence VEH-pretreated rats in the sucrose preference and EPM paradigms. Although $20 \mathrm{mg} / \mathrm{kg}$ nor-BNI may be high, this dose has been shown to be selective for KORs blockade (Endoh et al, 1992; Takemori et al, 1988), without influencing motor activity (Knoll et al, 2007). How MPH might increase KOR sensitivity is unknown. Exposure to cocaine and amphetamine increases dynorphin expression and decreases KOR expression, whereas prolonged exposure to these drugs decreases dynorphin, followed by KOR upregulation during drug cessation in the NAc and striatum (Spangler et al, 1996; Trujillo and Akil, 1990; Turchan et al, 1998; Unterwald et al, 1994). Given the psychostimulant-like properties of $\mathrm{MPH}$, it is feasible that MPH exposure may result in upregulation/increased sensitivity of KORs.

To summarize, this study shows that treatment with MPH during development results in decreased sensitivity to rewarding stimuli while enhancing a negative emotional state characterized by increased sensitivity to adverse situations in adulthood. In addition, this study shows that KOR stimulation, under certain experimental conditions, 
can intensify, whereas KOR blockade reverses these behavioral deficits. However, it is imperative to recognize that the MPH-induced behavioral profile described here was derived from normal rats, and similar experimental design and MPH treatment using established animal models of ADHD might yield different, even contrary results. Thus, these results should not be overinterpreted, because MPH remains a safe and effective pharmacotherapy for ADHD (Biederman and Faraone, 2005; Hyman, 2003). Despite the inherent difficulties in extrapolating to the human condition, these results underline the importance in the accurate diagnosis of ADHD before stimulant medication is commenced (Volkow and Insel, 2003). Together these findings underscore the need for further assessment of potential long-term neurobiological adaptations induced by early-life experiences that may contribute to the pathophysiology of neuropsychiatric disorders later in life, and further indicate that drugs attenuating dynorphin $/ \kappa$-receptor activity may be effective for the treatment of behavioral disorders associated with anxiety- and depression-like states.

\section{ACKNOWLEDGEMENTS}

This work was supported by grant no. 1R03DA020089 from the National Institute on Drug Abuse, a NARSAD Young Investigator Award, and a FYAP grant from Florida State University to CABG.

\section{DISCLOSURE/CONFLICT OF INTEREST}

The authors have no financial or competing interests to declare.

\section{REFERENCES}

Andersen SL, Arvanitogiannis A, Pliakas AM, LeBlanc C, Carlezon Jr WA (2002). Altered responsiveness to cocaine in rats exposed to methylphenidate during development. Nat Neurosci 5: 13-14.

Andersen SL, Navalta CP (2004). Altering the course of neurodevelopment: a framework for understanding the enduring effects of psychotropic drugs. Int J Dev Neurosci 22: 423-440.

Arnsten AF (2006). Stimulants: therapeutic actions in ADHD. Neuropsychopharmacology 31: 2376-2383.

Askenasy EP, Taber KH, Yang PB, Dafny N (2007). Methylphenidate (Ritalin): behavioral studies in the rat. Int J Neurosci 117: 757-794.

Badiani A, Rajabi H, Nencini P, Stewart J (2001). Modulation of food intake by the kappa opioid U-50,488H: evidence for an effect on satiation. Behav Brain Res 118: 179-186.

Berton O, McClung CA, Dileone RJ, Krishnan V, Renthal W, Russo $\mathrm{SJ}$ et al. (2006). Essential role of BDNF in the mesolimbic dopamine pathway in social defeat stress. Science 311: 864-868.

Biederman J, Faraone SV (2004). Attention deficit hyperactivity disorder: a worldwide concern. J Nerv Ment Dis 192: 453-454.

Biederman J, Faraone SV (2005). Attention-deficit hyperactivity disorder. Lancet 366: 237-248.

Bolaños CA, Barrot M, Berton O, Wallace-Black D, Nestler EJ (2003). Methylphenidate treatment during pre- and periadolescence alters behavioral responses to emotional stimuli at adulthood. Biol Psychiatry 54: 1317-1329.

Bolaños CA, Garmsen GM, Clair MA, McDougall SA (1996). Effects of the kappa-opioid receptor agonist U-50,488 on morphineinduced place preference conditioning in the developing rat. Eur J Pharmacol 317: 1-8.
Bolaños CA, Wiley MD, Maffeo ML, Powers KD, Kinka DW, Grausam KB et al. (2008). Antidepressant treatment can normalize adult behavioral deficits induced by early-life exposure to methylphenidate. Biol Psychiatry 63: 309-316.

Britton GB, Segan AT, Sejour J, Mancebo SE (2007). Early exposure to methylphenidate increases fear responses in an aversive context in adult rats. Dev Psychobiol 49: 265-275.

Carlezon Jr WA, Beguin C, DiNieri JA, Baumann MH, Richards MR, Todtenkopf MS et al. (2006). Depressive-like effects of the kappa-opioid receptor agonist salvinorin A on behavior and neurochemistry in rats. J Pharmacol Exp Ther 316: 440-447.

Carlezon Jr WA, Konradi C (2004). Understanding the neurobiological consequences of early exposure to psychotropic drugs: linking behavior with molecules. Neuropharmacology 47: 47-60.

Carlezon Jr WA, Mague SD, Andersen SL (2003). Enduring behavioral effects of early exposure to methylphenidate in rats. Biol Psychiatry 54: 1330-1337.

Carlezon Jr WA, Thome J, Olson VG, Lane-Ladd SB, Brodkin ES, Hiroi N et al. (1998). Regulation of cocaine reward by CREB. Science 282: 2272-2275.

Charntikov S, Halladay LR, Herbert MS, Marquez EM, McDougall SA (2008). Effects of dorsal striatal infusions of R(-)-propylnorapomorphine on kappa-opioid-mediated locomotor activity in the young rat: possible role of the indirect pathway. Neuroscience 155: 603-612.

Chavkin C, James IF, Goldstein A (1982). Dynorphin is a specific endogenous ligand of the kappa opioid receptor. Science 215: 413-415.

Collins RL, Zavala AR, Ingersoll VY, Duke MA, Crawford CA, McDougall SA (1998). Kappa opioid-mediated behavioral sensitization in the preweanling rat: relationship to Fos immunoreactivity. Psychopharmacology (Berl) 137: 282-291.

Corbett AD, Paterson SJ, McKnight AT, Magnan J, Kosterlitz HW (1982). Dynorphin and dynorphin are ligands for the kappasubtype of opiate receptor. Nature 299: 79-81.

Crawford CA, McDougall SA, Bolanos CA, Hall S, Berger SP (1995). The effects of the kappa agonist U-50488 on cocaine-induced conditioned and unconditioned behaviors and Fos immunoreactivity. Psychopharmacology (Berl) 120: 392-399.

Crawford CA, Villafranca SW, Cyr MC, Farley CM, Reichel CM, Gheorghe SL et al. (2007). Effects of early methylphenidate exposure on morphine- and sucrose-reinforced behaviors in adult rats: relationship to dopamine D2 receptors. Brain Res 1139: 245-253.

Cryan JF, Markou A, Lucki I (2002). Assessing antidepressant activity in rodents: recent developments and future needs. Trends Pharmacol Sci 23: 238-245.

Di Chiara G, Imperato A (1988). Opposite effects of mu and kappa opiate agonists on dopamine release in the nucleus accumbens and in the dorsal caudate of freely moving rats. J Pharmacol Exp Ther 244: 1067-1080.

Endoh T, Matsuura H, Tanaka C, Nagase H (1992). Norbinaltorphimine: a potent and selective kappa-opioid receptor antagonist with long-lasting activity in vivo. Arch Int Pharmacodyn Ther 316: 30-42.

Ettenberg A (2004). Opponent process properties of self-administered cocaine. Neurosci Biobehav Rev 27: 721-728.

Federici M, Geracitano R, Bernardi G, Mercuri NB (2005). Actions of methylphenidate on dopaminergic neurons of the ventral midbrain. Biol Psychiatry 57: 361-365.

Gualtieri CT, Wargin W, Kanoy R, Patrick K, Shen CD, Youngblood W et al. (1982). Clinical studies of methylphenidate serum levels in children and adults. J Am Acad Child Psychiatry 21: 19-26.

Horan P, Taylor J, Yamamura HI, Porreca F (1992). Extremely long-lasting antagonistic actions of nor-binaltorphimine (norBNI) in the mouse tail-flick test. J Pharmacol Exp Ther 260: 1237-1243. 
Hyman SE (2003). Methylphenidate-induced plasticity: what should we be looking for? Biol Psychiatry 54: 1310-1311.

Iñiguez SD, Warren BL, Neve RL, Nestler EJ, Russo SJ, BolañosGuzmán CA (2008). Insulin receptor substrate-2 in the ventral tegmental area regulates behavioral responses to cocaine. Synapse 122: 1172-1177.

Jewett DC, Woods JH (1995). Nor-binaltorphimine: an ultra-long acting kappa-opioid antagonist in pigeons. Behav Pharmacol 6: 815-820.

Knoll AT, Meloni EG, Thomas JB, Carroll FI, Carlezon Jr WA (2007). Anxiolytic-like effects of kappa-opioid receptor antagonists in models of unlearned and learned fear in rats. J Pharmacol Exp Ther 323: 838-845.

Koob GF, Sanna PP, Bloom FE (1998). Neuroscience of addiction. Neuron 21: 467-476.

Krishnan V, Han MH, Mazei-Robison M, Iniguez SD, Ables JL, Vialou $\mathrm{V}$ et al. (2008). AKT signaling within the ventral tegmental area regulates cellular and behavioral responses to stressful stimuli. Biol Psychiatry 64: 691-700.

Kuczenski R, Segal DS (2005). Stimulant actions in rodents: implications for attention-deficit/hyperactivity disorder treatment and potential substance abuse. Biol Psychiatry 57: 1391-1396.

Kuzmin A, Sandin J, Terenius L, Ogren SO (2000). Dose- and timedependent bimodal effects of kappa-opioid agonists on locomotor activity in mice. J Pharmacol Exp Ther 295: 1031-1042.

Kuzmin AV, Semenova S, Gerrits MA, Zvartau EE, Van Ree JM (1997). Kappa-opioid receptor agonist U50,488H modulates cocaine and morphine self-administration in drug-naive rats and mice. Eur J Pharmacol 321: 265-271.

Land BB, Bruchas MR, Lemos JC, Xu M, Melief EJ, Chavkin C (2008). The dysphoric component of stress is encoded by activation of the dynorphin kappa-opioid system. J Neurosci 28: 407-414.

Lucki I (1997). The forced swimming test as a model for core and component behavioral effects of antidepressant drugs. Behav Pharmacol 8: 523-532.

Mague SD, Andersen SL, Carlezon Jr WA (2005). Early developmental exposure to methylphenidate reduces cocaine-induced potentiation of brain stimulation reward in rats. Biol Psychiatry 57: $120-125$.

Mague SD, Pliakas AM, Todtenkopf MS, Tomasiewicz HC, Zhang Y, Stevens Jr WC et al. (2003). Antidepressant-like effects of kappa-opioid receptor antagonists in the forced swim test in rats. J Pharmacol Exp Ther 305: 323-330.

Maisonneuve IM, Archer S, Glick SD (1994). U50488, a kappa opioid receptor agonist, attenuates cocaine-induced increases in extracellular dopamine in the nucleus accumbens of rats. Neurosci Lett 181: 57-60.

Manzanares J, Lookingland KJ, Moore KE (1991). Kappa opioid receptor-mediated regulation of dopaminergic neurons in the rat brain. J Pharmacol Exp Ther 256: 500-505.

McDougall SA, Garmsen GM, Meier TL, Crawford CA (1997). Kappa opioid mediated locomotor activity in the preweanling rat: role of pre- and postsynaptic dopamine receptors. Psychopharmacology (Berl) 133: 62-68.

McLaughlin JP, Marton-Popovici M, Chavkin C (2003). Kappa opioid receptor antagonism and prodynorphin gene disruption block stress-induced behavioral responses. J Neurosci 23: 5674-5683.

Mucha RF, Herz A (1985). Motivational properties of kappa and $\mathrm{mu}$ opioid receptor agonists studied with place and taste preference conditioning. Psychopharmacology (Berl) 86: 274-280.

Nestler EJ, Barrot M, DiLeone RJ, Eisch AJ, Gold SJ, Monteggia LM (2002). Neurobiology of depression. Neuron 34: 13-25.

Nestler EJ, Carlezon Jr WA (2006). The mesolimbic dopamine reward circuit in depression. Biol Psychiatry 59: 1151-1159.
Olson VG, Zabetian CP, Bolanos CA, Edwards S, Barrot M, Eisch AJ et al. (2005). Regulation of drug reward by cAMP response element-binding protein: evidence for two functionally distinct subregions of the ventral tegmental area. J Neurosci 25: 5553-5562.

Pliakas AM, Carlson RR, Neve RL, Konradi C, Nestler EJ, Carlezon Jr WA (2001). Altered responsiveness to cocaine and increased immobility in the forced swim test associated with elevated cAMP response element-binding protein expression in nucleus accumbens. J Neurosci 21: 7397-7403.

Rey JM, Sawyer MG (2003). Are psychostimulant drugs being used appropriately to treat child and adolescent disorders? $\mathrm{Br} \mathrm{J}$ Psychiatry 182: 284-286.

Ruegg H, Yu WZ, Bodnar RJ (1997). Opioid-receptor subtype agonist-induced enhancements of sucrose intake are dependent upon sucrose concentration. Physiol Behav 62: 121-128.

Sampson D, Muscat R, Phillips G, Willner P (1992). Decreased reactivity to sweetness following chronic exposure to mild unpredictable stress or acute administration of pimozide. Neurosci Biobehav Rev 16: 519-524.

Shippenberg TS, Herz A (1986). Differential effects of mu and kappa opioid systems on motivational processes. NIDA Res Monogr 75: 563-566.

Shippenberg TS, Zapata A, Chefer VI (2007). Dynorphin and the pathophysiology of drug addiction. Pharmacol Ther 116: 306-321.

Spanagel R, Herz A, Shippenberg TS (1992). Opposing tonically active endogenous opioid systems modulate the mesolimbic dopaminergic pathway. Proc Natl Acad Sci USA 89: 2046-2050.

Spangler R, Ho A, Zhou Y, Maggos CE, Yuferov V, Kreek MJ (1996). Regulation of kappa opioid receptor mRNA in the rat brain by 'binge' pattern cocaine administration and correlation with preprodynorphin mRNA. Brain Res Mol Brain Res 38: 71-76.

Spear LP (2007). Assessment of adolescent neurotoxicity: rationale and methodological considerations. Neurotoxicol Teratol 29: $1-9$.

Spruijt BM, Welbergen P, Brakkee J, Gispen WH (1988). An ethological analysis of excessive grooming in young and aged rats. Ann N Y Acad Sci 525: 89-100.

Takemori AE, Ho BY, Naeseth JS, Portoghese PS (1988). Norbinaltorphimine, a highly selective kappa-opioid antagonist in analgesic and receptor binding assays. J Pharmacol Exp Ther 246: 255-258.

Trujillo KA, Akil H (1990). Pharmacological regulation of striatal prodynorphin peptides. Prog Clin Biol Res 328: 223-226.

Turchan J, Przewlocka B, Lason W, Przewlocki R (1998). Effects of repeated psychostimulant administration on the prodynorphin system activity and kappa opioid receptor density in the rat brain. Neuroscience 85: 1051-1059.

Unterwald EM, Rubenfeld JM, Kreek MJ (1994). Repeated cocaine administration upregulates kappa and mu, but not delta, opioid receptors. Neuroreport 5: 1613-1616.

Vitiello B (2001). Psychopharmacology for young children: clinical needs and research opportunities. Pediatrics 108: 983-989.

Volkow ND (2004). The reality of comorbidity: depression and drug abuse. Biol Psychiatry 56: 714-717.

Volkow ND, Insel TR (2003). What are the long-term effects of methylphenidate treatment? Biol Psychiatry 54: 1307-1309.

Wooters TE, Neugebauer NM, Rush CR, Bardo MT (2008). Methylphenidate enhances the abuse-related behavioral effects of nicotine in rats: intravenous self-administration, drug discrimination, and locomotor cross-sensitization. Neuropsychopharmacology 33: 1137-1148.

Yano M, Steiner H (2005). Topography of methylphenidate (ritalin)-induced gene regulation in the striatum: differential effects on c-fos, substance P and opioid peptides. Neuropsychopharmacology 30: 901-915. 
You ZB, Herrera-Marschitz M, Terenius L (1999). Modulation of neurotransmitter release in the basal ganglia of the rat brain by dynorphin peptides. J Pharmacol Exp Ther 290: 1307-1315.

Zhang H, Shi YG, Woods JH, Watson SJ, Ko MC (2007). Central kappa-opioid receptor-mediated antidepressant-like effects of

nor-Binaltorphimine: behavioral and BDNF mRNA expression studies. Eur J Pharmacol 570: 89-96.

Zito JM, Safer DJ, dosReis S, Gardner JF, Boles M, Lynch F (2000). Trends in the prescribing of psychotropic medications to preschoolers. JAMA 283: 1025-1030. 